\title{
Bioavailability of Microplastics to Marine Zooplankton: Effect of Shape and Infochemicals
}

\author{
Zara L. R. Botterell, Nicola Beaumont, Matthew Cole, Frances E. Hopkins, Michael Steinke, \\ Richard C. Thompson, and Penelope K. Lindeque*
}

Cite This: https://dx.doi.org/10.1021/acs.est.0c02715

Read Online

\section{ACCESS | Llll Metrics \& More | 回 Article Recommendations | (s) Supporting Information}

ABSTRACT: The underlying mechanisms that influence microplastic ingestion in marine zooplankton remain poorly understood. Here, we investigate how microplastics of a variety of shapes (bead, fiber, and fragment), in combination with the algal-derived infochemicals dimethyl sulfide (DMS) and dimethylsulfoniopropionate (DMSP), affect the ingestion rate of microplastics in three species of zooplankton, the copepods Calanus helgolandicus and Acartia tonsa and larvae of the European lobster Homarus gammarus. We show that shape affects microplastic bioavailability to different species of zooplankton, with each species ingesting significantly more of a certain shape: C. helgolandicus-fragments

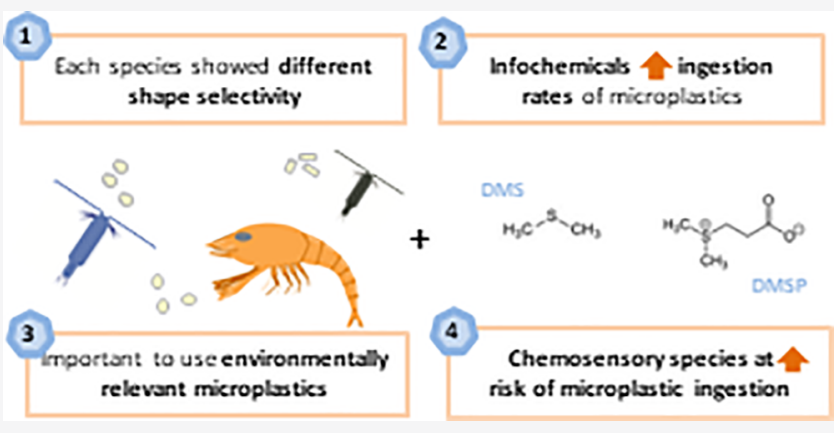
$(P<0.05)$; A. tonsa-fibers $(P<0.01)$; H. gammarus larvaebeads $(P<0.05)$. Thus, different feeding strategies between species may affect shape selectivity. Our results also showed significantly increased ingestion rates by $C$. helgolandicus on all microplastics that were infused with DMS $(P<0.01)$ and by $H$. gammarus larvae and $A$. tonsa on DMS-infused fibers and fragments $(P<0.05)$. By using a range of more environmentally relevant microplastics, our findings highlight how the feeding strategies of different zooplankton species may influence their susceptibility to microplastic ingestion. Furthermore, our novel study suggests that species reliant on chemosensory cues to locate their prey may be at an increased risk of ingesting aged microplastics in the marine environment.

\section{INTRODUCTION}

Microplastic (microscopic plastic, $1 \mu \mathrm{m}$ to $5 \mathrm{~mm}$ ) is abundant and widespread in the marine environment and has been identified as a contaminant of global environmental and economic concern. ${ }^{1-3}$ The risks that larger plastic debris presents to marine organisms have been well documented, ${ }^{4-7}$ yet there still remain knowledge gaps regarding the impact of microplastics. ${ }^{1}$ Microplastics are not uniform; they are a complex array of different shapes, sizes, and polymers. ${ }^{8}$ Microbeads and fibers can enter the environment via multiple pathways with direct release from waste water treatment works being a substantial source through the use of plastics in cosmetics and synthetic clothing. ${ }^{9,10}$ The degradation of larger plastic debris due to ultraviolet (UV) radiation and wave action can form irregularly shaped microplastic fragments. ${ }^{10,11}$ Due to their small size, microplastics are bioavailable via ingestion to a wide range of organisms. ${ }^{12}$ Ingestion of microplastics has been recorded in many marine species including cetaceans, ${ }^{13,14}$ seabirds, ${ }^{15}$ molluscs, ${ }^{16}$ and zooplankton. ${ }^{17,18}$ In species at lower trophic levels, such as zooplankton, ingested microplastics have been shown to cause several detrimental effects, including reduced feeding behavior, growth, and fecundity. ${ }^{19-21}$
Zooplankton are a crucial food source and provide an important link in the marine food web between phytoplankton and higher trophic levels. ${ }^{22}$ Zooplankton comprise many different species of marine invertebrates and some vertebrates (e.g., fish larvae), including those species that spend their entire life cycle (holoplankton), and those with larval stages (meroplankton), in the plankton. Meroplanktonic species develop into adults that are often important constituents of fin-fish and shellfish stocks, which are ecologically and economically important. ${ }^{23}$ Previous laboratory studies have shown that zooplankton have the capacity to ingest several different types of microplastics, ${ }^{17,24}$ which has also been documented in zooplankton from the wild. ${ }^{18,25,26}$ While many studies have investigated the microplastic presence and effect of ingestion, the underlying mechanisms and factors that influence plastic ingestion still remain poorly understood.

Received: April 29, 2020

Revised: August 26, 2020

Accepted: August 26, 2020 

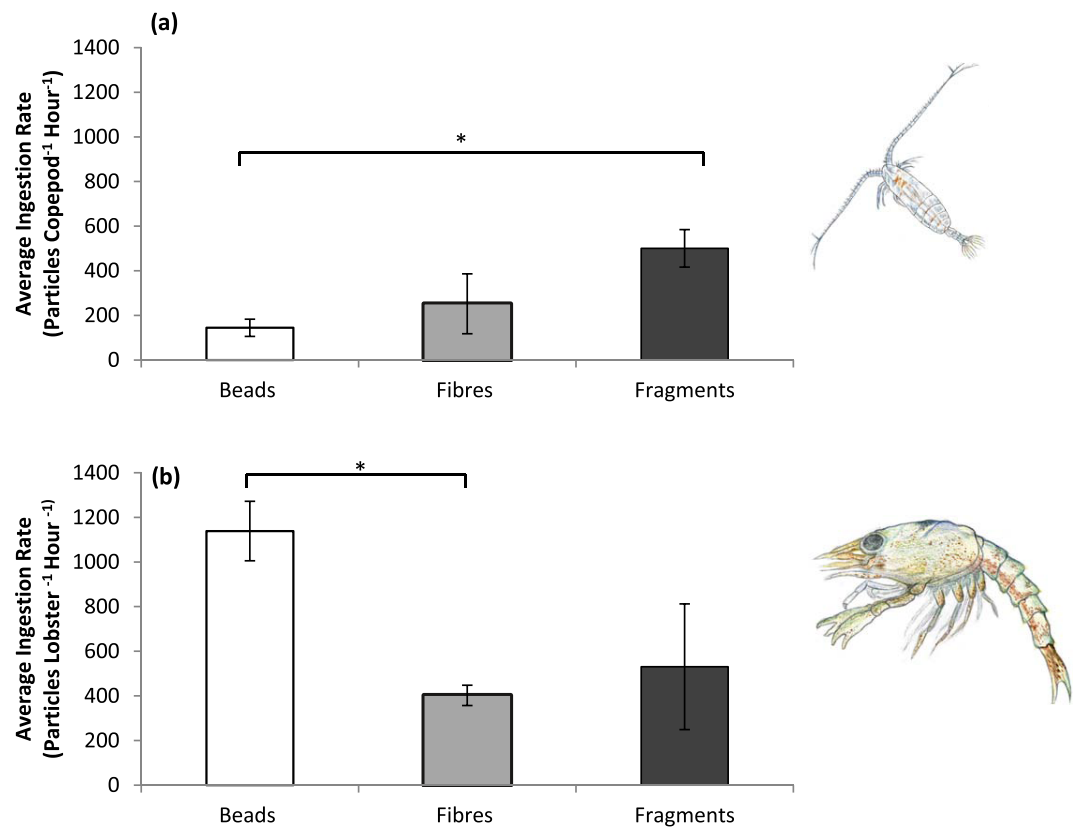

(c)
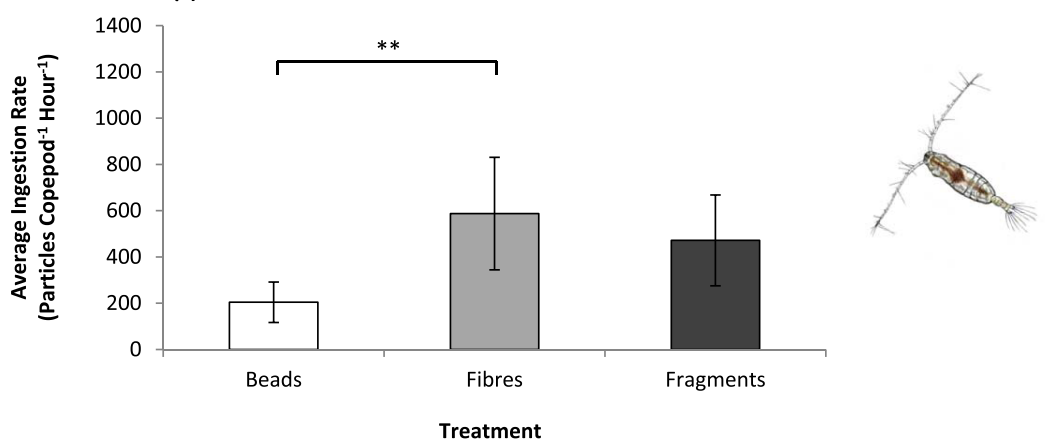

Figure 1. Ingestion rates \pm standard error (SE) (particles individual ${ }^{-1} \mathrm{~h}^{-1}$ ) of differently shaped microplastics including beads, fibers, and fragments for (a) C. helgolandicus, (b) H. gammarus, and (c) A. tonsa. The asterisks denote the level of significant difference in ingestion rates, $* P \leq$ $0.05, * * P \leq 0.01$. Illustrations by Vivienne Botterell.

Food selectivity has been widely evidenced in copepods, with the capacity to discriminate between algal prey and microplastics. ${ }^{27,28}$ There are several abiotic and biotic factors that can affect the biological availability (bioavailability) of microplastics to an organism. ${ }^{8,29}$ While the overlap in size of the microplastic and the gape of the individual's mouth is key to ingestion and capture efficiency, other factors such as microplastic shape may affect handling and the capacity for ingestion. ${ }^{8,28}$ Many previous laboratory studies have used polystyrene microspheres that have been shown to be readily ingested by a number of species, indicating that this shape is bioavailable to a broad range of taxa. ${ }^{17,19,30}$ However, several studies from the field investigating microplastic ingestion in zooplankton found that microfibers were most commonly ingested. $^{18,25,26}$ It is unclear whether this shape is more bioavailable or whether it is the most abundant microplastic in the areas sampled. Recent research has shown that differently shaped microplastics can alter the severity of certain biological effects. $^{31,32}$ For example, in sheepshead minnow larvae ( Cyprinodon variegatus), irregularly shaped microplastic fragments negatively affect swimming behavior, decreasing the total distance traveled and their maximum velocity. ${ }^{32}$ Additionally Cole et al. showed that the presence of fibrous microplastics can significantly alter prey selectivity in the copepod Calanus finmarchicus. ${ }^{31}$ These negative effects could reduce food intake and the available energy for growth, development, and reproductive success.

There is growing evidence that chemosensory cues, not just physical factors, could influence the bioavailability of microplastics. $^{24,33-35}$ In the marine environment, plastic can provide a durable substrate for biofouling biota that may produce infochemicals. $^{36,37}$ Colonization by infochemical-producing microorganisms, and subsequently the formation and growth of biofilms, could lead to plastic debris acquiring a chemical signal that is attractive to those species that use chemosensory mechanisms when locating, identifying, and ingesting food. ${ }^{33,38-40}$ One such chemical is dimethyl sulfide (DMS), a marine trace gas derived from dimethylsulfoniopropionate (DMSP) that is produced by phytoplankton. ${ }^{39}$ DMS concentrations typically range from 1 to $7 \mathrm{nM}$ in the surface ocean, with peak concentrations in the North Atlantic Ocean during June-July owing to the annual coccolithophore and dinoflagellate blooms. ${ }^{41}$ Recent research has identified that many species demonstrate foraging behavior in the presence of DMS, including loggerhead turtles, ${ }^{42}$ seabirds, ${ }^{33}$ hard corals, ${ }^{34}$ and copepods. ${ }^{43}$ The chemical precursor DMSP has also been shown to induce swimming and aggregation behavior in forage fish. ${ }^{44,45}$ Breckels et al. demonstrated that DMS plumes 
stimulated the grazing behavior response of Calanus helgolandicus at concentrations of $1.8-13.1 \mathrm{nM}^{46}$ Recent research by Procter et al. showed that $C$. helgolandicus ingested significantly more DMS-infused microfibers than virgin microfibers. ${ }^{35}$ This indicates that complex chemosensory cues may have a role in mediating foraging behavior and therefore consumption of microplastic debris.

Currently, little is known about what factors influence the uptake of microplastics by zooplankton. To better understand the mechanisms behind microplastic ingestion, it is vital to use microplastics that are more representative of those found in the marine environment. ${ }^{8,47}$ In the present study, we investigate the effect of microplastic shape and the presence of the infochemicals DMSP and DMS on microplastic ingestion by three species of zooplankton: the widely distributed suspension feeder C. helgolandicus, a temperate calanoid copepod and dominant mesozooplankton species in the North Atlantic; the globally distributed calanoid copepod Acartia tonsa, an ambush and suspension feeder; and the ambush feeder larvae of Homarus gammarus (European lobster) - a species of both economic and social importance in the U.K. We test the hypotheses that (1) species-specific ingestion is significantly different between microplastics of various shapes and (2) infusion of microplastics with DMS or DMSP significantly increases the bioavailability and ingestion of the differently shaped microplastics.

\section{METHODS}

Zooplankton Sampling and Husbandry. Zooplankton samples were collected from the Western Channel Observatory station L4, U.K. $\left(50^{\circ} 15^{\prime} \mathrm{N}, 4^{\circ} 13^{\prime} \mathrm{W}\right)$ using $200 \mu \mathrm{m}$ WP2 plankton nets in February 2019. The samples were transported within insulated boxes, containing natural seawater, to Plymouth Marine Laboratory (Plymouth, U.K.) within $3 \mathrm{~h}$ of sampling. Adult female $C$. helgolandicus were identified using a dissecting microscope (Wild M5-49361; $\times 20$ to $\times 50$ magnification) through assessment of their life stage, size, shape, and distinct genital pore. Individuals were carefully picked out using Storkbill forceps and transferred to $5 \mathrm{~L}$ beakers containing filtered seawater. Seawater was filtered via a filtration rig through a $0.22 \mu \mathrm{m}$ nitrocellulose filter (Millipore). European lobster larvae (H. gammarus) (stage 1) were obtained in August 2018 from the National Lobster Hatchery, Padstow, U.K. Adult A. tonsa were provided from culture by Reefshotz, U.K. in September 2019. Female A. tonsa were identified using a dissecting microscope through assessment of their size, shape. and distinct genital pore. All samples were processed and experiments were conducted in controlledtemperature (CT) laboratories matched to the ambient sea surface temperature (SST) of $18{ }^{\circ} \mathrm{C}$ (H. gammarus, August 2018) and $10{ }^{\circ} \mathrm{C}$ (C. helgolandicus, February 2019) or culture temperature of $21{ }^{\circ} \mathrm{C}$ (A. tonsa).

Preparation of Microplastics. Virgin $20 \mu \mathrm{m}$ polystyrene beads (Spherotech, Illinois), fresh-cut virgin $20 \mu \mathrm{m} \times 10 \mu \mathrm{m}$ nylon fibers (Goodfellow Cambridge Ltd., prepared following Cole method $\left.^{48}\right)$, and virgin $\leq 20 \mu \mathrm{m}$ nylon fragments (Goodfellow Cambridge Ltd.) were used to represent our three shape classifications (Supporting Information, Figure 1). All microplastics used were yellow in color. The different polymers were used as at the time no nylon microbeads were available. While the size of the microplastics was kept as uniform as possible, due to the different shapes, surface area (beads: $1.26 \times 10^{3} \mu \mathrm{m}^{2}$, fibers: $0.79 \times 10^{3} \mu \mathrm{m}^{2}$, fragments:
$>1.26 \times 10^{3} \mu \mathrm{m}^{2}$ ) and volume (beads: $4.19 \times 10^{3} \mu \mathrm{m}^{2}$, fibers: $1.57 \times 10^{3} \mu \mathrm{m}^{2}$, fragments: $<4.19 \times 10^{3} \mu \mathrm{m}^{2}$ ) varied.

For the experiments with $C$. helgolandicus and $A$. tonsa, glass DURAN experimental bottles $(500 \mathrm{~mL}$, total volume $615 \mathrm{~mL}$ ) were $\sim 75 \%$ filled with $0.22 \mu \mathrm{m}$ filtered seawater (FSW) and spiked with the $15 \mathrm{~mL}$ vials of either beads, fibers, or fragments of virgin (control) or DMSP- or DMS-infused beads, fibers, or fragments. The bottles were then carefully filled to the brim with FSW, which resulted in an overall concentration of 80 microplastics $\mathrm{mL}^{-1}$ in each of the experimental bottles. All microplastic treatments were incubated in MilliQ water in 15 $\mathrm{mL}$ gas-tight vials in a refrigerator at $3{ }^{\circ} \mathrm{C}$ for 3 days before use in grazing experiments.

Environmentally relevant concentrations of DMSP and DMS were chosen for our infused treatments. ${ }^{41,49}$ DMSPinfused beads/fibers/fragments were prepared by infusion in an aqueous $20 \mathrm{nM}$ DMSP solution (Centrum voor Analyse, Spectroscopie and Synthese, Rijksuniversiteit Groningen, The Netherlands). DMS-infused beads/fibers/fragments were prepared by infusion in a $5 \mathrm{nM}$ aqueous DMS solution (Sigma-Aldrich Company Ltd.). The addition of the infused microplastics to the experimental flasks was performed by directly adding the entire $15 \mathrm{~mL}$ solution to the flask at the start of the experiment. This addition to the $600 \mathrm{~mL}$ of seawater in the flask resulted in a negligible calculated change in ambient DMSP/DMS concentrations of $0.49 \mathrm{nM}$ (DMSP) and $0.12 \mathrm{nM}$ (DMS).

The same process was used for the European lobster larvae. However, due to their cannibalistic nature under limited food availability, larvae were treated individually using smaller experimental bottles $(50 \mathrm{~mL})$ and gas-tight vials $(1.9 \mathrm{~mL})$. The concentrations of microplastics, DMSP, and DMS remained the same.

At the microplastic concentrations used in this experiment, we were unable to measure the final concentrations of DMS/ DMSP fused to the microplastics as the levels are far below the detection limit of our methods.

Grazing Experiments. For all species and for each shape of microplastic, the grazing experiments consisted of (1) a virgin microplastic control group; (2) a DMSP-infused microplastic treatment group; and (3) a DMS-infused microplastics treatment group. Following the initial results with $H$. gammarus larvae, we refined the protocol in the $C$. helgolandicus and $A$. tonsa experiments to include additional controls of (4) DMSP and microplastics added to the experimental bottles separately but concurrently (DMSP noninfused); and (5) DMS and microplastics added to the experimental bottles separately but concurrently (DMS noninfused). Copepods and lobster larvae were starved for a period of $24 \mathrm{~h}$ prior to the experiment.

In the $C$. helgolandicus and $A$. tonsa experiment, there were six replicates per treatment for virgin, infused/noninfused DMSP and DMS treatment groups, using copepods that had been acclimatized to the laboratory conditions for 2 days. The algae Dunaliella tertiolecta, Prorocentrum micans, and Thalassiosira rotula were provided as a source of prey during the acclimation period for $C$. helgolandicus. They were cultured on $\mathrm{f} / 2$ media, with addition of silica for $T$. rotula, and maintained at $13{ }^{\circ} \mathrm{C}$ at a $16: 8$ light/dark cycle. A. tonsa copepods were maintained on their culture media of Tetraselmis suecica, Isochrysis galbana (T-Iso), and Chaetoceros muelleri.

Grazing experiments were carried out in gas-tight $500 \mathrm{~mL}$ Pyrex bottles (total volume $615 \mathrm{~mL}$ ), filled to the brim with 


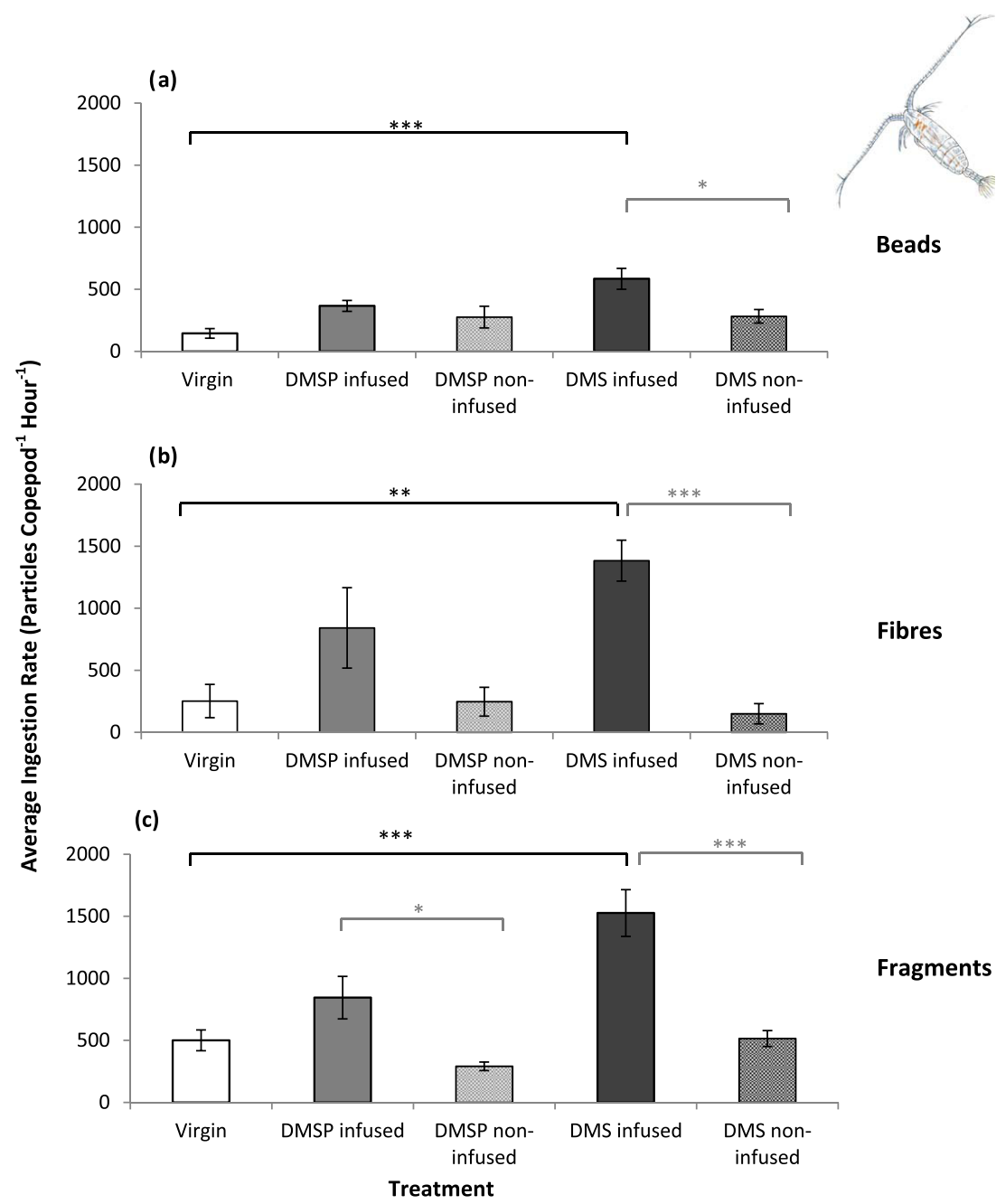

Figure 2. C. helgolandicus ingestion rates \pm SE (particles copepod ${ }^{-1} h^{-1}$ ) of differently shaped microplastics: (a) beads, (b) fibers, and (c) fragments, with the different treatments of virgin, DMSP infused, DMS infused, DMSP noninfused, and DMS noninfused. The black significance bars relate to virgin controls and the gray significance bars relate to noninfused controls. The asterisks denote the levels of significant difference in the ingestion rates, $* P \leq 0.05, * * P \leq 0.01, * * * P \leq 0.001$. Illustration by Vivienne Botterell.

$0.2 \mu \mathrm{m}$ filtered seawater (FSW). Five healthy adult female $C$. helgolandicus or A. tonsa were transferred to each experimental bottle, followed by the addition of microplastics with or without DMSP or DMS. Copepods were not added to the $T_{0}$ (time zero, beginning of the experiment) experimental bottles. The experimental bottles were secured to a plankton wheel, rotated at $5 \mathrm{rpm}$, and left for $6 \mathrm{~h}$ in the dark in a CT room at $10{ }^{\circ} \mathrm{C}$ (C. helgolandicus) or $21{ }^{\circ} \mathrm{C}($ A. tonsa). After $6 \mathrm{~h}$, the experiment was stopped and the copepods were removed from each experimental bottle by gently passing the contents of the bottle through a $150 \mu \mathrm{m}$ mesh into a beaker. The water was returned to the bottle and stored at $3{ }^{\circ} \mathrm{C}$ for microplastic enumeration using a FlowCam (Fluid Imaging Technologies Ltd.; see below). The mesh containing the copepods was examined under a dissection microscope and any mortality was recorded. Copepods were then transferred into an Eppendorf tube containing $1 \mathrm{~mL}$ of $4 \%$ recycled formalin.

In the $H$. gammarus larvae experiment, there were ten replicates per treatment for virgin, DMSP and DMS treatment groups, using lobster larvae that had been acclimatized to the laboratory conditions for 2 days. Frozen plankton (TMC Gamma Blister Red Plankton) was provided as a source of prey during the acclimation period.
Grazing experiments were carried out in gas-tight $50 \mathrm{~mL}$ Pyrex bottles (total volume $65 \mathrm{~mL}$ ), filled to the brim with 0.2 $\mu \mathrm{m}$ filtered seawater (FSW). One healthy European lobster larva was transferred to each experimental bottle, followed by the addition of microplastics with or without DMSP or DMS. Lobster larvae were not added to the $T_{0}$ experimental bottles. The experimental bottles were secured to a plankton wheel, rotated at $5 \mathrm{rpm}$, and left for $3 \mathrm{~h}$ in the dark in a CT room at $18{ }^{\circ} \mathrm{C}$. We then followed the same process as above in the experiments, preserving the individuals in $1 \mathrm{~mL}$ of $4 \%$ recycled formalin.

A FlowCAM (VS-4 series) was used in autoimage mode to count the number of microplastic particles within a sample and determine the plastic concentration. For the analysis, $40 \mathrm{~mL}$ of the sample was pumped at $2 \mathrm{~mL} \mathrm{~min}^{-1}$ through the flow chamber fitted with a $100 \mu \mathrm{m} \times 2 \mathrm{~mm}$ flow cell and a $10 \mathrm{x}$ objective lens, which captured the images of the particles at 20 frames $\mathrm{s}^{-1}$. FlowCAM uses the software program VisualSpreadsheet ( $\mathrm{v} 3.4$ ), which can sort the images by selected characteristics such as length. Any images that were not microplastic particles were deleted and the remaining images saved as a new list, which would then be used to generate a count of particles $\mathrm{mL}^{-1}$. The FlowCAM was used to determine 


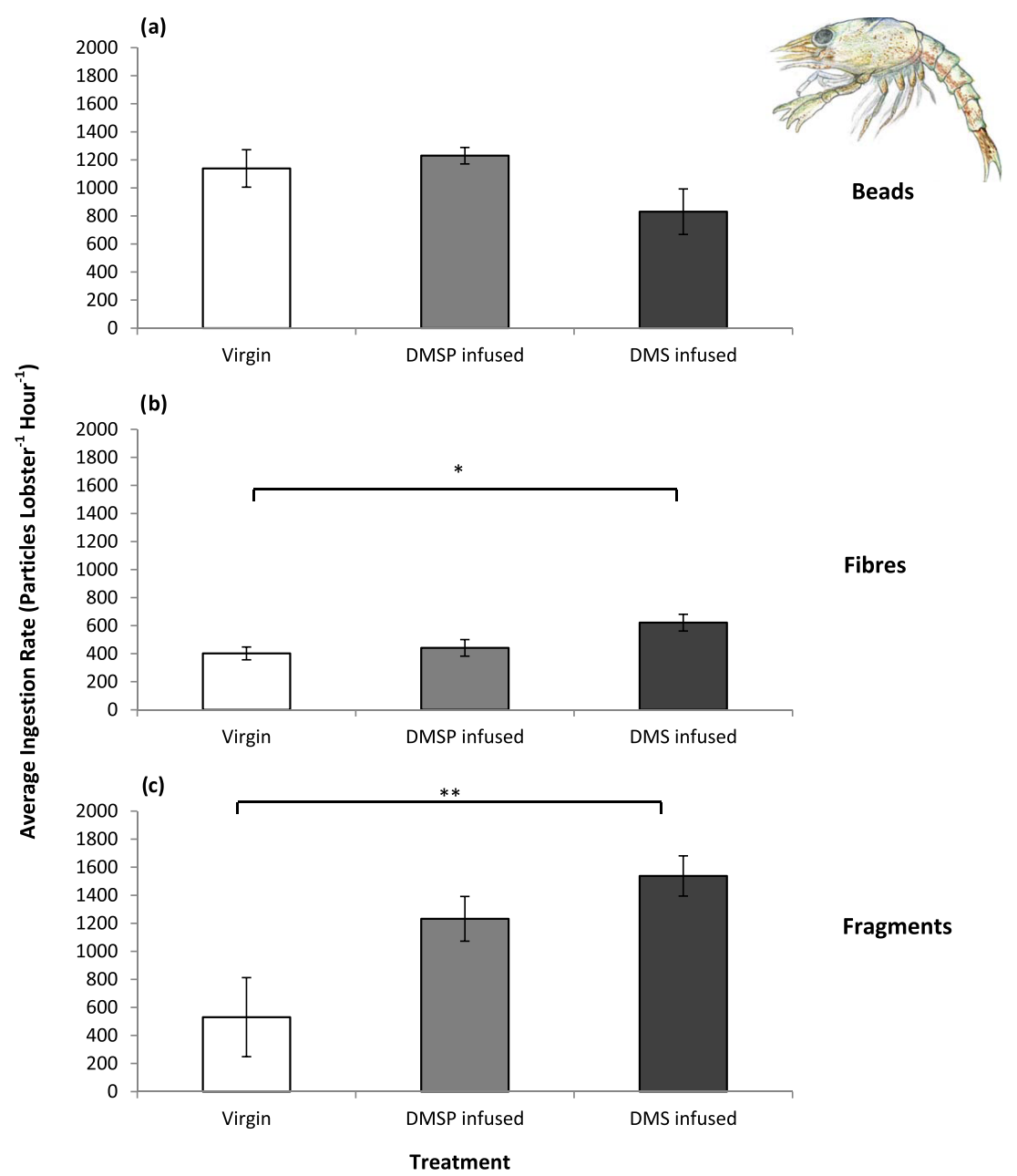

Figure 3. H. gammarus (larvae) ingestion rates $\pm \mathrm{SE}$ (particles lobster ${ }^{-1} \mathrm{~h}^{-1}$ ) of the virgin, DMSP-infused, and DMS-infused microplastics for all three shapes: (a) beads, (b) fibers, and (c) fragments. The asterisks denote the levels of significant difference in the ingestion rates, $* P \leq 0.05, * * P$ $\leq 0.01$. Illustration by Vivienne Botterell.

the initial microplastic concentration $\left(T_{0}\right)$ and the postexperimental microplastic concentration $\left(T_{6}\right)$.

Grazing rates were estimated by comparing changes in the abundance of the microplastics over the experimental period for differently shaped microplastics with or without the addition of DMSP and DMS. Ingestion rates (particles organism $^{-1} \mathrm{~h}^{-1}$ ) were calculated using an adapted version of the Frost (1972) equation, which accounted for the absence of prey growth during the incubations. ${ }^{35,50}$

The grazing coefficient $(g)$ was calculated from eq 1

$$
g=0-\log \frac{T_{6}}{T_{0}} \times \frac{1}{T}
$$

where $T_{0}$ is the concentration of microplastics $\mathrm{mL}^{-1}$ at the beginning of the experiment, $T_{6}\left(T_{3}\right.$ for $H$. gammarus larvae experiment) is the concentration of microplastics $\mathrm{mL}^{-1}$ at the end of the experiment (after 3 or $6 \mathrm{~h}$ ), and $T$ is the time in hours (Supporting Information, Table 1). The clearance rates $\left(F, \mathrm{~mL}\right.$ organism $\left.{ }^{-1} \mathrm{~h}^{-1}\right)$ were calculated from eq 2

$$
F=\frac{V \times g}{n}
$$

where $V$ is the volume of the experimental bottle $(\mathrm{mL}), g$ is the grazing coefficient calculated in eq 1 , and $n$ is the number of zooplankton per bottle. The ingestion rate $(I)$ is then calculated using eq 3

$$
I=F \times T_{0}
$$

Statistical Analysis. All data were analyzed using Microsoft Excel (2016) and the statistical software R (version 3.4.1, $\mathrm{R}$ Development Core Team 2017). Data were tested for normality using a Shapiro-Wilk test and homogeneity of variance was visually inspected to satisfy parametric requisites. A one-way analysis of variance (one-way ANOVA) and Tukey's post hoc tests were used to compare the ingestion rates from grazing experiments. The significance level was set at $\alpha=0.05$.

\section{RESULTS}

Influence of Shape on Microplastic Ingestion. The copepod $C$. helgolandicus demonstrated a significant variation in the ingestion rates of differently shaped microplastics (Figure 1a, one-way ANOVA $\left(F_{(2,15)}=3.78, P=0.047\right)$ ). A post hoc Tukey test showed that the fragments were ingested significantly more than the beads $(P=0.043)$. The fragments were ingested at a mean rate $( \pm S E)$ of $500.3( \pm 83.9)$ fragments copepod ${ }^{-1} \mathrm{~h}^{-1}$, in comparison to the mean number of beads, $144.5( \pm 38.4)$ beads copepod ${ }^{-1} \mathrm{~h}^{-1}$, and fibers, 251.9 $( \pm 134.0)$ fibers copepod ${ }^{-1} \mathrm{~h}^{-1}$ (Figure 1a). 


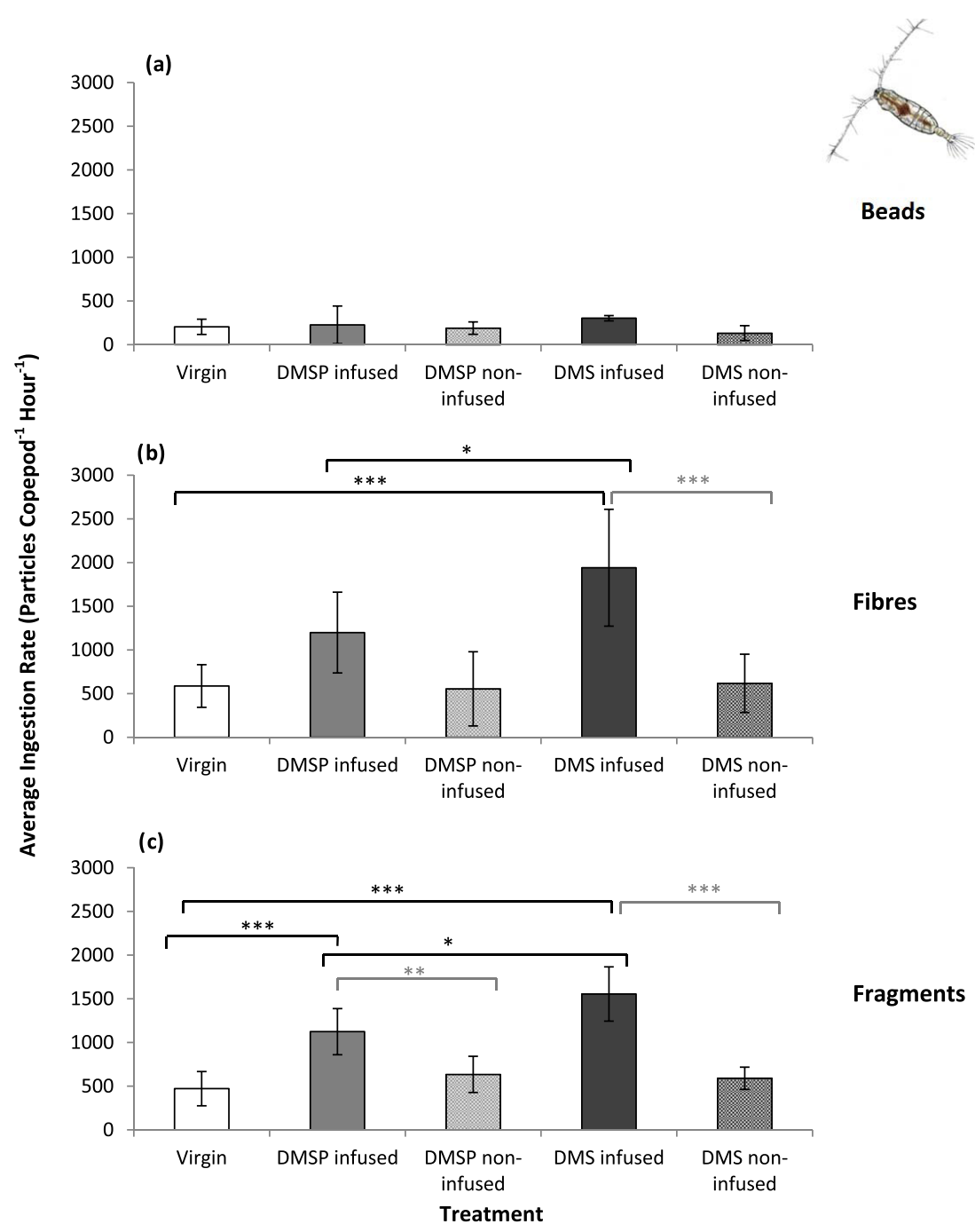

Figure 4. A. tonsa ingestion rates $\pm \mathrm{SE}$ (particles copepod ${ }^{-1} \mathrm{~h}^{-1}$ ) of differently shaped microplastics: (a) beads, (b) fibers, and (c) fragments, with the different treatments of virgin, DMSP infused, DMS infused, DMSP noninfused, and DMS noninfused. The black significance bars relate to virgin controls and the gray significance bars relate to noninfused controls. The asterisks denote the levels of significant difference in the ingestion rates, $* P \leq 0.05, * * P \leq 0.01$, $* * * P \leq 0.001$. Illustration by Vivienne Botterell.

H. gammarus larvae also exhibited a significant variation in the ingestion rates of the different microplastic shapes (Figure 1 b, one-way ANOVA $\left.\left(F_{(2,26)}=4.36, P=0.0233\right)\right)$. A post hoc Tukey test showed that the beads were ingested significantly more than the fibers $(P=0.026)$ and substantially more than the fragments $(P=0.074)$. The beads were ingested at a mean rate $( \pm S E)$ of $1138.7( \pm 133.4)$ beads lobster ${ }^{-1} \mathrm{~h}^{-1}$, in comparison to the mean number of fibers, $402.3( \pm 45.6)$ fibers lobster ${ }^{-1} \mathrm{~h}^{-1}$, and fragments, $530.7( \pm 281.7)$ fragments lobster ${ }^{-1} \mathrm{~h}^{-1}$ (Figure $1 \mathrm{~b}$ ).

The copepod $A$. tonsa demonstrated a significant variation in the ingestion rates of differently shaped microplastics (Figure $1 c$, one-way ANOVA $\left.\left(F_{(2,15)}=6.6, P=0.009\right)\right)$. A post hoc Tukey test showed that the fibers were ingested significantly more than the beads $(P=0.008)$ and substantially more than the fragments $(P=0.06)$. The fibers were ingested at a mean rate $( \pm S E)$ of $587.5( \pm 243.4)$ fibers copepod ${ }^{-1} \mathrm{~h}^{-1}$, in comparison to the mean number of beads, $204.1( \pm 87.3)$ beads copepod ${ }^{-1} \mathrm{~h}^{-1}$, and fragments, 471.5 ( \pm 196.4) fragments copepod ${ }^{-1} \mathrm{~h}^{-1}$ (Figure 1c).

Influence of Infochemicals on Microplastic Ingestion. The copepod C. helgolandicus demonstrated an increase in the average ingestion rates of the microplastics that had been infused with DMSP and DMS, across all three shapes, in comparison to virgin and also noninfused microplastics (infochemical and microplastics added to the experimental bottles concurrently) (Figure 2). Analysis showed that there were significant differences between the infochemical treatment groups with all three shapes (beads: Figure 2a, one-way ANOVA $\left(F_{(4,25)}=6.235, P=0.0013\right)$, fibers: Figure $2 \mathrm{~b}\left(F_{(4,25)}\right.$ $=8.214, P \leq 0.001)$, and fragments: Figure $2 \mathrm{c}\left(F_{(4,25)}=15.21\right.$, $P \leq 0.001)$ ). A post hoc Tukey test showed that DMS infusion significantly increased the ingestion rates of the beads (Figure $2 \mathrm{a}, P \leq 0.001$ ), fibers (Figure $2 \mathrm{~b}, P \leq 0.01$ ), and fragments (Figure $2 c, P \leq 0.001$ ) in comparison to the virgin control treatments. In addition, it showed that all microplastics that were infused with DMS were ingested significantly more than those that were not infused with DMS (beads: Figure 2a, $P \leq$ 0.05 , fibers: Figure $2 b, P \leq 0.001$, and fragments: Figure $2 c, P$ $\leq 0.001)$. This was also found for DMSP-infused and noninfused fragments (Figure $2 c, P \leq 0.05$ ). There were no significant differences between the virgin control and the noninfused microplastic control for both infochemicals across all microplastic shapes. 
In the DMSP- and DMS-infused treatments, the average ingestion rate of the fibers and fragments by H. gammarus larvae increased (Figure 3). Analysis showed that there were significant differences between the infochemical treatment groups for both fibers (Figure $3 \mathrm{~b}$, one-way $\operatorname{ANOVA}\left(F_{(2,27)}=\right.$ 4.481, $P=0.021)$ ) and fragments (Figure $3 c$, one-way ANOVA $\left.\left(F_{(2,27)}=6.372, P=0.0054\right)\right)$. A post hoc Tukey test showed that the presence of DMS significantly increased the ingestion rates of the fibers (Figure $3 \mathrm{~b}, P \leq 0.05$ ) and fragments (Figure $3 c, P \leq 0.01)$ in comparison to the control virgin treatments. The presence of the infochemicals had no effect on the ingestion rates of the beads (Figure 3a, one-way ANOVA $\left.\left(F_{(2,26)}=2.863, P=0.075\right)\right)$.

In the DMSP- and DMS-infused treatments, the average ingestion rate of the fibers and fragments by $A$. tonsa increased (Figure 4). Analysis showed that there were significant differences between the infochemical treatment groups for both fibers (Figure $4 \mathrm{~b}$, one-way ANOVA $\left(F_{(2,25)}=11.6, P \leq\right.$ $0.001))$ and fragments (Figure $4 c$, one-way ANOVA $\left(F_{(2,25)}=\right.$ 21.2, $P \leq 0.001)$ ). A post hoc Tukey test showed that the presence of DMS significantly increased the ingestion rates of the fibers (Figure $4 b, P \leq 0.05$ ) and fragments (Figure $4 c, P \leq$ 0.01 ) in comparison to the control virgin treatments. The presence of the infochemicals had no effect on the ingestion rates of the beads (Figure 4a, one-way ANOVA $\left(F_{(2,25)}=1.7, P\right.$ $=0.18)$ ). In addition, it showed that the fibers and fragments that were infused with DMS were ingested significantly more than those that were not infused with DMS (Figure $4 \mathrm{~b}, P \leq$ 0.001 , and fragments: Figure $4 c, P \leq 0.001)$. This was also found for the DMSP-infused and noninfused fragments (Figure $4 c, P \leq 0.01$ ). There were no significant differences between the virgin control and the noninfused microplastic control for both infochemicals across all microplastic shapes.

\section{DISCUSSION}

Our study reveals that both shape and the infusion of infochemicals can affect the ingestion rate of microplastics in C. helgolandicus, A. tonsa, and H. gammarus larvae. Each species selectively ingested significantly more of a certain microplastic shape (Figure 1), indicating that shape is an important factor that influences microplastic bioavailability. C. helgolandicus ingested more fragments; $H$. gammarus ingested more beads; and $A$. tonsa ingested the most fibers. We further observed that infusion with the infochemical DMS significantly increased the ingestion rates of microplastics in all three species (Figures 2-4). This highlights that chemosensory species utilizing DMS as an infochemical may be at an increased risk of microplastic debris ingestion. These findings add to the growing evidence of the importance of testing environmentally relevant microplastics in zooplankton grazing studies in contrast to the predominately used virgin beads, to fully elucidate the mechanisms behind microplastic ingestion. ${ }^{8}$

Effect of Microplastic Shape on Its Bioavailability to Zooplankton. Previous laboratory research has shown that many species of zooplankton will readily ingest microplastic beads including $C$. helgolandicus and $A$. tonsa. ${ }^{17,51}$ However, microplastic ingestion has not previously been observed in $H$. gammarus larvae. The fragments and fibers have also been shown to be ingested by C. helgolandicus. ${ }^{28,31}$ Furthermore, in wild copepods sampled in the natural environment, irregularly shaped and fibrous microplastics have been identified. ${ }^{18,25}$ However, it is unclear whether these microplastics from the wild samples are due to prey selectivity of the species, differences in gut retention time, or simply a representation of the most prevalent microplastic in the environment under investigation.

Our results show that while all microplastic shapes were ingested, each of the species selectively ingested one shape preferentially over the others (Figure 1). The selectivity of the species could be explained by the different feeding strategies, with particular shapes being easier to handle, or species-specific capacities to ingest. C. helgolandicus ingested the most fragments, $H$. gammarus the most beads, and A. tonsa the most fibers. C. helgolandicus is a suspension feeder, using appendages around their mouths to generate a feeding current. ${ }^{52,53}$ Whereas $A$. tonsa is an ambush feeder, a complex grazing behavior requiring a stimulus to optimize capturing prey items yet avoiding nonfood items, but can also switch to suspension feeding when consuming small phytoplankton by generating a feeding current. ${ }^{54,55}$ It is the smallest of the three species used in these experiments and therefore may have found the smaller diameter of the fibers $(10 \mu \mathrm{m})$ easier to ingest. Additionally, it is possible that differently shaped microplastics may generate different eddies, through disturbances in the feeding current or water flow, which may be more or less attractive to species with different feeding strategies. Similarly to A. tonsa, H. gammarus larvae are also thought to be ambush feeders consuming both phytoplankton and zooplankton. ${ }^{56}$ Unlike copepods, which have a singular naupliar eye that is light sensitive, lobster larvae have two compound eyes, which are not only light sensitive but also have a large view angle and are able to detect fast movement. ${ }^{5,58}$ This more developed spatial vision may aid the lobster in prey selection and subsequently may have played a role in the selectivity of the microplastic beads over the other shapes. The microplastic shape may also resemble the species' natural prey source. The microplastics used in this current study overlapped in size with the species prey. The beads and fragments may resemble spherical algae and the fibers could resemble chain-forming diatoms. ${ }^{28}$ Shape selectivity could also be explained by species shifting their prey preference. ${ }^{31}$ Recent research by Cole et al. and Coppock et al. suggest that Calanus species may shift prey selectivity to avoid ingesting microalgae that are of a similar size and shape to the microplastics that they were exposed to, potentially to avoid consuming the plastic particles. ${ }^{28,31}$ However, future behavioral experiments are recommended to further understand this mechanism of microplastic shape selectivity.

Certain microplastic shapes have been shown to have more adverse effects than others in species of zooplankton, with previous research highlighting negative effects on swimming behavior by the fragments ${ }^{32}$ and feeding behavior by the fibers. $^{31}$ It is crucial to understand which shapes have the highest bioavailability in a species to understand the effect commonly ingested microplastic shapes could have on the health of the individual as any negative effects could reduce food intake and available energy for growth, development, and reproductive success. Future experiments should consider differences in gut retention time between differently shaped microplastics as certain shapes may be retained longer than others. This is imperative to understanding whether the microplastics we find in zooplankton sampled in the natural environment were due to selectivity of the species, representative of the microplastics present in the environment, or are retained for longer in the gut. The length of time the microplastics are retained for has implications not only for the 
health of the individual but also for the transport of the microplastics through the water column by diel vertical migration of zooplankton and also through the food web when zooplankton is consumed by predators. ${ }^{28,59}$

Role of Infochemicals in Increasing the Bioavailability of the Microplastics. To investigate whether these chemicals would stimulate grazing, C. helgolandicus, A. tonsa, and $H$. gammarus larvae were exposed to microplastics (beads, fibers, and fragments) that had been infused in artificial DMS and DMSP solutions of environmentally relevant concentrations. Our results show that the presence of the infochemical DMS can lead to significant increases in the ingestion rate of microplastics in three species of zooplankton. This indicates that chemosensory species utilizing DMS as an infochemical may be at an increased risk of microplastic debris ingestion.

In C. helgolandicus, the ingestion rates of all three microplastic shapes were significantly increased when infused with DMS and while not significant, DMSP infusion also substantially increased microplastics uptake. H. gammarus larvae exhibited a similar pattern to A. tonsa, with significantly more microplastic fibers and fragments ingested when infused with DMS. However, DMSP infusion only substantially increased microplastic fragment ingestion in $H$. gammarus and neither infochemical affected the ingestion rate of the microplastic beads. However, DMSP infusion did significantly increase the ingestion rate of both fibers and fragments in $A$. tonsa, but like DMS had no effect on bead ingestion. While the majority of the microplastics infused with DMS were ingested at a higher rate in all species, DMS infusion had no effect on the ingestion of the microplastic beads by the lobster larvae. However, the microplastic beads in the virgin treatment group were ingested at the highest rate in comparison to the fibers and fragments, which implies that the microplastic shape had a higher bioavailability and an overriding effect on the chemoattractive potential of DMS. It is possible that the more developed vision of the larvae likely aided in prey detection and selection, and that the larvae used a range of chemo- and mechanoreceptors in combination with visual cues. This highlights that in some species, microplastic shape, based on the particles that are easier to handle or mimic the preferred prey items, may present a greater bioavailability than other factors including attraction by infochemicals.

Following the initial results with $H$. gammarus larvae, we refined the protocol in the $C$. helgolandicus and $A$. tonsa experiments, to include additional controls in order to investigate whether simply the presence of infochemicals in the surrounding seawater induced an increase in the ingestion rates. Here, the addition of virgin, noninfused microplastics to the experimental flasks was performed separately but concurrently to the addition of $15 \mathrm{~mL}$ of DMS or DMSP solution (see Methods, Preparation of Microplastics). However, there was no significant difference in the ingestion rates between the virgin controls and the noninfused controls across all microplastic shapes. Furthermore, our results (Figures 2 and 4) show that there was a significant difference between the noninfused DMS controls and the infused DMS treatments for almost all three different shapes of the microplastics. This therefore suggests that it is not just the presence of DMS in the seawater, but the presence of DMS on the plastic itself that stimulates increased ingestion.

In the marine environment, the infochemicals DMSP and DMS could be present on the plastic surface due to biofilm formation by DMSP/DMS-producing microorganisms, which form part of the diverse microbial community of the plastisphere. ${ }^{38}$ Many of these organisms within the plastisphere are important prey items readily consumed by several species of zooplankton. ${ }^{60}$ This could increase the ability of zooplankton to locate the plastic particles if they mimic the scent of natural prey and in turn could increase consumption of the microplastics. It is important to note that these experiments are a simplification of the natural environment separating visual biofilm effects from chemical cues associated with DMSP/DMS. There still remains a significant knowledge gap in assessing the ability of the microplastics to gain an infochemical signature through the formation of a biofilm. This work seeks to further understand the interspecies response to DMSP/DMS, yet future investigation is still required to understand the response to additional infochemicals and importantly the detection thresholds of the chemosensory organisms.

Environmental Relevance and Risk Assessment. In this study, we demonstrate that both the shape and the presence of infochemicals can affect the ingestion rate of the microplastics in three species of zooplankton. This research highlights the importance of using a greater diversity of the environmentally relevant microplastics in laboratory experiments. For our infochemical infusion experiments, we used environmentally relevant concentrations of DMSP and DMS. While this triggered increased uptake of the microplastics in all three of the species, currently there is very little understanding of the interspecies response to other infochemicals, limited knowledge on the detection threshold of chemosensory species, and a poor understanding of the chemical gradients emanating from the microscopic particles. The microplastics used in this study were chosen to be as similar as possible (i.e., size and color); however, due to the use of different shapes, they did vary slightly in volume and surface area, which could affect the ingestion rates in some species. It is possible that those microplastics with a greater surface area, such as fragments, may gain a greater infochemical signature. Similarly, polymer type could also affect the ingestion rates. Different polymers have been shown to develop different microbial biofilm communities, which in turn could produce different infochemicals. ${ }^{61}$ While we used nylon fibers and fragments we also used polystyrene beads as we were unable to find a nylon equivalent. The concentration of the microplastics used in this study exceeds those currently observed in the marine environment; however, there is very little environmental information relating to microplastics in the size range of 10$30 \mu \mathrm{m}$ due to technical difficulties in sampling, extracting, and identifying such particles. ${ }^{31}$ However, where data is available, they suggest an inverse relationship between particle size and abundance, and hence, the smaller the microplastics, the larger their concentration. ${ }^{62}$ Recent research by Lindeque et al. has demonstrated that the $333 \mu \mathrm{m}$ nets commonly used for microplastic sampling underestimate microplastic abundance, particularly for $<333 \mu \mathrm{m}$ microplastics that are within the optimal prey size range of numerous marine organisms. ${ }^{63}$ While it is important to investigate the risk that environmentally relevant microplastic concentrations pose to marine organisms, it is essential to understand the mechanisms by which microplastics become bioavailable to a species, can cause harm, identify end points, and understand the sensitivity of different species at every life stage, and it is also crucial to conduct these studies at elevated/future scenario concen- 
trations. ${ }^{8,31}$ Such research is key to establishing no-effect thresholds for the development of effective risk assessments for species, populations, and the ecosystem.

\section{ASSOCIATED CONTENT}

\section{SI Supporting Information}

The Supporting Information is available free of charge at https://pubs.acs.org/doi/10.1021/acs.est.0c02715.

Images of the microplastics and microplastic concentration data at $T_{0}, T_{3}$, and $T_{6}(\mathrm{PDF})$

\section{AUTHOR INFORMATION}

\section{Corresponding Author}

Penelope K. Lindeque - Marine Ecology and Biodiversity, Plymouth Marine Laboratory, Plymouth PL1 3DH, U.K.; Email: pkw@pml.ac.uk

\section{Authors}

Zara L. R. Botterell - Marine Ecology and Biodiversity, Plymouth Marine Laboratory, Plymouth PL1 3DH, U.K.; School of Life Sciences, University of Essex, Colchester CO4 3SQ, U.K.; 다이.org/0000-0003-1001-3203

Nicola Beaumont - Plymouth Marine Laboratory, Plymouth PL1 3DH, U.K.

Matthew Cole - Marine Ecology and Biodiversity, Plymouth Marine Laboratory, Plymouth PL1 3DH, U.K.; 이이.org/ 0000-0001-5910-1189

Frances E. Hopkins - Marine Biogeochemistry and Ocean Observations, Plymouth Marine Laboratory, Plymouth PL1 3DH, U.K.

Michael Steinke - School of Life Sciences, University of Essex, Colchester CO4 3SQ, U.K.

Richard C. Thompson - Marine Biology and Ecology Research Centre (MBERC), School of Biological and Marine Sciences, University of Plymouth, Plymouth PL4 8AA, U.K.

Complete contact information is available at: https://pubs.acs.org/10.1021/acs.est.0c02715

\section{Notes}

The authors declare no competing financial interest.

\section{ACKNOWLEDGMENTS}

We would like to thank the captain and crew of Plymouth Marine Laboratory's RV Plymouth Quest for assistance during sampling, Andrea McEvoy for guidance on zooplankton identification, Elaine Fileman for instruction on the use of FlowCam, and Joceline Triner for access to facilities at the University of Plymouth. We thank Vivienne Botterell for the zooplankton illustrations and for permission to use them in our figures. ZLRB was supported by the Natural Environment Research Council (NERC) through the EnvEast Doctoral Training Partnership (grant number: NE/L002582/1). We thank the editor and three anonymous reviewers for their constructive and insightful feedback that improved the manuscript.

\section{REFERENCES}

(1) Thompson, R. C.; Olson, Y.; Mitchell, R. P.; Davis, A.; Rowland, S. J.; John, A. W. G.; McGonigle, D.; Russell, A. E. Lost at Sea: Where Is All the Plastic? Science 2004, 304, 838.

(2) MSFD GES Technical Subgroup on Marine Litte. Marine Litter - technical recommendations for the implementation of MSFD requirements. UR-Scientific and Technical Research Series, 2011, $91 \mathrm{p}$.

(3) Worm, B.; Lotze, H. K.; Jubinville, I.; Wilcox, C.; Jambeck, J. Plastic as a Persistent Marine Pollutant. Annu. Rev. Environ. Resour. 2017, 42, 1-26.

(4) Duncan, E. M.; Botterell, Z. L. R.; Broderick, A. C.; Galloway, T. S.; Lindeque, P. K.; Nuno, A.; Godley, B. J. A global review of marine turtle entanglement in anthropogenic debris: a baseline for further action. Endanger Species Res. 2017, 34, 431-448.

(5) Laist, D. W. Impacts of Marine Debris: Entanglement of Marine Life in Marine Debris Including a Comprehensive List of Species with Entanglement and Ingestion Records. In Marine Debris, Springer: New York, NY, 1997, pp 99-139.

(6) Baulch, S.; Perry, C. Evaluating the impacts of marine debris on cetaceans. Mar. Pollut. Bull. 2014, 80, 210-221.

(7) Lavers, J. L.; Bond, A. L.; Hutton, I. Plastic ingestion by fleshfooted shearwaters (Puffinus carneipes): Implications for fledgling body condition and the accumulation of plastic-derived chemicals. Environ. Pollut. 2014, 187, 124-129.

(8) Botterell, Z. L. R.; Beaumont, N.; Dorrington, T.; Steinke, M.; Richard, C.; Lindeque, P. K. Bioavailability and effects of microplastics on marine zooplankton: a review. Environ. Pollut. 2019, 245, 98-110.

(9) Napper, I. E.; Thompson, R. C. Release of synthetic microplastic plastic fibres from domestic washing machines: Effects of fabric type and washing conditions. Mar. Pollut. Bull. 2016, 112, 39-45.

(10) Thompson, R. C. Sources, Distribution, and Fate of Microscopic Plastics in Marine Environments. In Hazardous Chemicals Associated with Plastics in the Marine Environment; Springer: Cham, 2019; Vol. 78, pp 121-133.

(11) Barnes, D. K. A.; Galgani, F.; Thompson, R. C.; Barlaz, M. Accumulation and fragmentation of plastic debris in global environments. Philos. Trans. R. Soc. London 2009, 364, 1985-1998.

(12) Galloway, T. S.; Cole, M.; Lewis, C. Interactions of microplastic debris throughout the marine ecosystem. Nat. Ecol. Evol. 2017, 1, 18.

(13) Besseling, E.; Foekema, E. M.; Van Franeker, J. A.; Leopold, M. F.; Kühn, S.; Bravo Rebolledo, E. L.; Heße, E.; Mielke, L.; Ijzer, J.; Kamminga, P.; Koelmans, A. A. Microplastic in a macro filter feeder: Humpback whale Megaptera novaeangliae. Mar. Pollut. Bull. 2015, 95, $248-252$.

(14) Lusher, A. L.; Hernandez-Milian, G.; O’Brien, J.; Berrow, S.; O'Connor, I.; Officer, R. Microplastic and macroplastic ingestion by a deep diving, oceanic cetacean: The True's beaked whale Mesoplodon mirus. Environ. Pollut. 2015, 199, 185-191.

(15) Amélineau, F.; Bonnet, D.; Heitz, O.; Mortreux, V.; Harding, A. M. A.; Karnovsky, N.; Walkusz, W.; Fort, J.; Gremillet, D. Microplastic pollution in the Greenland Sea: Background levels and selective contamination of planktivorous diving seabirds. Environ. Pollut. 2016, 219, 1131-1139.

(16) Browne, M. A.; Dissanayake, A.; Galloway, T. S.; Lowe, D. M.; Thompson, R. C. Ingested Microscopic Plastic Translocates to the Circulatory System of the Mussel, Mytilus edulis (L.). Environ. Sci. Technol. 2008, 42, 5026-5031.

(17) Cole, M.; Lindeque, P. K.; Fileman, E.; Halsband, C.; Goodhead, R.; Moger, J.; Galloway, T. S. Microplastic ingestion by zooplankton. Environ. Sci. Technol. 2013, 47, 6646-55.

(18) Desforges, J.-P. W.; Galbraith, M.; Ross, P. S. Ingestion of Microplastics by Zooplankton in the Northeast Pacific Ocean. Arch. Environ. Contam. Toxicol. 2015, 69, 320-30.

(19) Lee, K.; Shim, W. J.; Kwon, O. Y.; Kang, J. Size-Dependent Effects of Micro Polystyrene Particles in the Marine Copepod Tigriopus japonicus. Environ. Sci. Technol. 2013, 47, 11278-11283.

(20) Cole, M.; Lindeque, P.; Fileman, E.; Halsband, C.; Galloway, T. $S$. The impact of polystyrene microplastics on feeding, function and fecundity in the marine copepod Calanus helgolandicus. Environ Sci Technol. 2015, 49, 1130-7. 
(21) Lo, H. K. A.; Chan, K. Y. K. Negative effects of microplastic exposure on growth and development of Crepidula onyx. Environ. Pollut. 2018, 233, 588-595.

(22) Kiørboe, T. How zooplankton feed: Mechanisms, traits and trade-offs. Biol. Rev. 2011, 86, 311-39.

(23) Worm, B.; Barbier, E. B.; Beaumont, N.; Duffy, J. E.; Folke, C.; Halpern, B. S.; Jackson, J. B. C.; Lotze, H. K.; Micheli, F.; Palumbi, S. R.; Sala, E.; Selkoe, K. A.; Stachowicz, J. J.; Watson, R. Impacts of biodiversity loss on ocean ecosystem services. Science 2006, 314, 787790.

(24) Vroom, R. J. E.; Koelmans, A. A.; Besseling, E.; Halsband, C. Aging of microplastics promotes their ingestion by marine zooplankton. Environ. Pollut. 2017, 231, 987-996.

(25) Steer, M.; Cole, M.; Thompson, R. C.; Lindeque, P. K. Microplastic ingestion in fish larvae in the western English Channel. Environ. Pollut. 2017, 226, 250-259.

(26) Sun, X.; Li, Q.; Zhu, M.; Liang, J.; Zheng, S.; Zhao, Y. Ingestion of microplastics by natural zooplankton groups in the northern South China Sea. Mar. Pollut. Bull. 2017, 115, 217-24.

(27) Huntley, M. E.; Barthel, K. G.; Star, J. L. Particle rejection by Calanus pacificus: discrimination between similarly sized particles. Mar. Biol. 1983, 74, 151-60.

(28) Coppock, R. L.; Galloway, T. S.; Cole, M.; Fileman, E. S.; Queirós, A. M.; Lindeque, P. K. Microplastics alter feeding selectivity and faecal density in the copepod, Calanus helgolandicus. Sci. Total Environ. 2019, 687, 780-9.

(29) Wright, S. L.; Thompson, R. C.; Galloway, T. S. The physical impacts of microplastics on marine organisms: A review. Environ Pollut. 2013, 178, 483-492.

(30) Cole, M.; Galloway, T. S. Ingestion of Nanoplastics and Microplastics by Pacific Oyster Larvae. Environ. Sci. Technol. 2015, 49, $14625-14632$.

(31) Cole, M.; Coppock, R.; Lindeque, P. K.; Altin, D.; Reed, S.; Pond, D. W.; Sørensen, L.; Galloway, T. S.; Booth, A. M. Effects of Nylon Microplastic on Feeding, Lipid Accumulation, and Moulting in a Coldwater Copepod. Environ. Sci. Technol. 2019, 53, 7075-7082.

(32) Choi, J. S.; Jung, Y. J.; Hong, N. H.; Hong, S. H.; Park, J. W. Toxicological effects of irregularly shaped and spherical microplastics in a marine teleost, the sheepshead minnow (Cyprinodon variegatus). Mar. Pollut. Bull. 2018, 129, 231-240.

(33) Savoca, M. S.; Wohlfeil, M. E.; Ebeler, S. E.; Nevitt, G. A. Marine plastic debris emits a keystone infochemical for olfactory foraging seabirds. Sci. Adv. 2016, 2, No. e1600395.

(34) Allen, A. S.; Seymour, A. C.; Rittschof, D. Chemoreception drives plastic consumption in a hard coral. Mar. Pollut. Bull. 2017, 124, 198-205.

(35) Procter, J.; Hopkins, F. E.; Fileman, E. S.; Lindeque, P. K. Smells good enough to eat: Dimethyl sulfide (DMS) enhances copepod ingestion of microplastics. Mar. Pollut. Bull. 2019, 138, 1-6.

(36) Barnes, D. K. A. Biodiversity: Invasions by marine life on plastic debris. Nature 2002, 416, 808-809.

(37) Lobelle, D.; Cunliffe, M. Early microbial biofilm formation on marine plastic debris. Mar. Pollut. Bull. 2011, 62, 197-200.

(38) Zettler, E. R.; Mincer, T. J.; Amaral-Zettler, L. A. Life in the "plastisphere": Microbial communities on plastic marine debris. Environ. Sci. Technol. 2013, 47, 7137-7146.

(39) Yoch, D. C. Dimethylsulfoniopropionate: Its Sources, Role in the Marine Food Web, and Biological Degradation to Dimethylsulfide. Appl. Environ. Microbiol. 2002, 68, 5804-5815.

(40) Pohnert, G.; Steinke, M.; Tollrian, R. Chemical cues, defence metabolites and the shaping of pelagic interspecific interactions. Trends Ecol. Evol. 2007, 22, 198-204.

(41) Lana, A.; Bell, T. G.; Simó, R.; Vallina, S. M.; Ballabrera-Poy, J.; Kettle, A. J.; Dachs, J.; Bopp, L.; Saltzman, E. S.; Stefels, J.; Johnson, J. E.; Liss, P. S. An updated climatology of surface dimethlysulfide concentrations and emission fluxes in the global ocean. Global Biogeochem. Cycles 2011, 25, 1-17.

(42) Endres, C. S.; Lohmann, K. J. Perception of dimethyl sulfide (DMS) by loggerhead sea turtles: A possible mechanism for locating high-productivity oceanic regions for foraging. J. Exp. Biol. 2012, 215, 3535-3538.

(43) Steinke, M.; Stefels, J.; Stamhuis, E. Dimethyl sulfide triggers search behavior in copepods. Limnol. Oceanogr. 2006, 51, 1925-1930.

(44) DeBose, J. L.; Nevitt, G. A.; Dittman, A. H. Rapid Communication: Experimental evidence that Juvenile Pelagic Jacks (Carangidae) respond behaviorally to DMSP. J. Chem. Ecol. 2010, 36, 326-8.

(45) DeBose, J. L.; Lema, S. C.; Nevitt, G. A. Dimethylsulfoniopropionate as a foraging cue for reef fishes. Science 2008, 319, 1356.

(46) Breckels, M. N.; Roberts, E. C.; Archer, S. D.; Malin, G.; Steinke, M. The role of dissolved infochemicals in mediating predator-prey interactions in the heterotrophic dinoflagellate Oxyrrhis marina. J. Plankton Res. 2011, 33, 629-639.

(47) Phuong, N. N.; Zalouk-Vergnoux, A.; Poirier, L.; Kamari, A.; Châtel, A.; Mouneyrac, C.; Al, E. Is there any consistency between the microplastics found in the field and those used in laboratory experiments? Environ. Pollut. 2016, 211, 111-123.

(48) Cole, M. A novel method for preparing microplastic fibers. Sci. Rep. 2016, 6, No. 34519.

(49) Archer, S. D.; Cummings, D. G.; Llewellyn, C. A.; Fishwick, J. $\mathrm{R}$. Phytoplankton taxa, irradiance and nutrient availability determine the seasonal cycle of DMSP in temperate shelf seas. Mar. Ecol. Prog. Ser. 2009, 394, 111-124.

(50) Frost, B. W. Effects of size and concentration of food particles on the feeding behaviour of the marine planktonic copepod Calanus pacificus. Limnol. Oceanogr. 1972, 17, 805-815.

(51) Syberg, K.; Nielsen, A.; Khan, F. R.; Banta, G. T.; Palmqvist, A.; Jepsen, P. M. Microplastic potentiates triclosan toxicity to the marine copepod Acartia tonsa (Dana). J. Toxicol. Environ. Health, Part A 2017, 80, 1369-71.

(52) Cannon, B. Y. H. G. On the feeding mechanism of the copepod, Calanus finmarchicus and Diaptomus gracilis. J. Exp. Biol. 1928, 6, 131-44.

(53) Paffenhöfer, G.-A.; Strickler, J. R.; Alcaraz, M. Suspensionfeeding by herbivorous calanoid copepods: A cinematographic study. Mar. Biol. 1982, 67, 193-199.

(54) Donaghay, P. L.; Small, L. F. Food selection capabilities of the estuarine copepod Acartia clausi. Mar. Biol. 1979, 52, 137-146.

(55) Saiz, E.; Kiorboe, T. Predatory and suspension feeding of the copepod Acartia tonsa in turbulent environments. Mar. Ecol. Prog. Ser. 1995, 122, 147-158.

(56) Juinio, M. A. R.; Cobb, J. S. Natural diet and feeding habits of the postlarval lobster Homarus americanus. Mar. Ecol. Prog. Ser. 1992, $85,83-91$.

(57) Stearns, D. E.; Forward, R. B. Photosensitivity of the calanoid copepod Acartia tonsa. Mar. Biol. 1988, 253, 247-253.

(58) Meyer-Rochow, V. B. Larval and adult eye of the Western Rock Lobster (Panulirus longipes). Cell Tissue Res. 1975, 162, 439-57.

(59) Setälä, O.; Fleming-Lehtinen, V.; Lehtiniemi, M. Ingestion and transfer of microplastics in the planktonic food web. Environ. Pollut. 2014, 185, 77-83.

(60) Amaral-Zettler, L. A.; Zettler, E. R.; Mincer, T. J. Ecology of the plastisphere. Nat. Rev. Microbiol. 2020, 18, 139-151.

(61) Pinto, M.; Langer, T. M.; Huffer, T.; Hofmann, T.; Herndl, G. J. The composition of bacterial communities associated with plastic biofilms differs between different polymers and stages of biofilm succession. PLoS One 2019, 14, No. e0217165.

(62) Enders, K.; Lenz, R.; Stedmon, C. A.; Nielsen, T. G. Abundance, size and polymer composition of marine microplastics $\geq 10 \mu \mathrm{m}$ in the Atlantic Ocean and their modelled vertical distribution. Mar. Pollut. Bull. 2015, 100, 70-81.

(63) Lindeque, P. K.; Cole, M.; Coppock, R. L.; Lewis, C. N.; Miller, R. Z.; Watts, A. J. R.; Wilson-McNeal, A.; Wright, S. L.; Galloway, T. $S$. Are we underestimating microplastic abundance in the marine environment? A comparison of microplastic capture with nets of. Environ Pollut. 2020, 265, No. 114721. 